\title{
Journal of Sustainable Development
}

www.ccsenet.org/journal.html

July 2008

\section{A Study on the Pollination Ecology of Eremurus inderiensis}

\author{
Junfeng Fan \\ College of Life Science \\ Shihezi University \\ Shihezi 832003, China \\ Tel: 86-0993-205-7218 E-mail: meiwei-5@163.com \\ Miao Ma \\ The Key Oasis Eco-Agriculture Laboratory of Xinjiang Production and Construction Group \\ Shihezi University \\ Shihezi 832003, China \\ Tel: 86-0993-205-7218Ｅ-mail: mamiaogg@126.com
}

\begin{abstract}
Two-year study on the pollination ecology of Eremurus inderiensis reveals that the florescence of eremurus is from the middle ten days of May to the first ten years of June, anthesis of a single flower lasts one day. When the weather is rainy and the highest temperature is less than 20 centigrade, anthesis of a single flower can last two days. Pollen dispersal period of single flower can last for 4 to 5 hours from 10:30 to 15:00 local time with the duration of pollen dispersal for single anther approximately 40min. The heterotypical maturation of 6 anthers could significantly prolong the pollen dispersal period of a single flower, suggesting an adaptation to the habitat of Eremurus inderiensis in the desert where the pollinators are uncertain. The main pollinators belong to Apidae, Halictidae, Syrphidae, Bombyliidae and Therevidae. Pollen/Ovule ( $\mathrm{P} / \mathrm{O})$ reveals that Eremurus inderiensis is obligate xenogamy.
\end{abstract}

Keywords: Eremurus inderiensis, Pollination ecology, Heterotypical maturation of stamen, $\mathrm{P} / \mathrm{O}$

Eremurus inderiensis, which lives in the dry desert, belongs to Liliaceae, Eremurus (Cui, et al., 1996). Eremurus inderiensis burgeons in the early spring when the snow melts (from the end of March to the beginning of April). The life cycle of Eremurus inderiensis is about 60 days; this kind of ephemeral plant contributes greatly to the stabilization of sand (Wang, et al., 2003). But the frequent human activities, including engineering, reclamation of waste land, industrial discharge and over grazing, severely influence the survival and reproduction of ephemeral plants, more and more ephemeral plants are dying out (Zhang, et al., 1998). So it is important to effectively protect this special kind of biological species. At present, little study was carried out in the pollination ecology of Eremurus inderiensis, study on the ecological adaptation mechanism of Eremurus inderiensis in the desert from the angle of pollination ecology will provide us with more clues about the possible mechanism for this species to accommodate the desert and provide more data for us to protect the species.

\section{Materials and methods}

\subsection{Materials}

The wild E. inderiensis in the south of Guerbantonggute desert from 2006 to 2007.

\subsection{Methods}

\subsubsection{Flowering Phenology and observation of floral features}

\subsubsection{Flowering Phenology}

Chose well growing E. inderiensis that was about to flower from the natural population and recorded the whole florescence in 2004 and 2005.

\subsubsection{Floral features}

Feature of single flower (floral design): 20 flowers were chosen to be labeled and observed from 8:00 to 20:00 to record the characteristic of anthesis and anther dehiscence, the variation in perianth structure during the blooming, the heterotypical maturation of six anthers, the structure, color and smell of flower, and the reward for the pollinators. 
Feature of flower group (floral display): the number of blooming flowers at one moment and their arrangement in the anthotaxy.

\subsubsection{Pollination feature}

\subsubsection{Abiotic pollination medium}

In the direction down the wind, simple pollen catcher (glass slide with medical vaseline wiped on the surface) was set up every 1 meter starting from the pollen source, resulting in two parallel lines including 70 glass slides each. Pollen catching time was from 9:00 to 17:00; the number of pollen was examined and recorded under the optic microscope (Olympus) to analyze the influence of wind on pollination(Douglas K L.and Cruden R W., 1994).

\subsubsection{Biotic pollination medium}

25 flowers were randomly chosen from five healthy $E$. inderiensis and labeled. The insect species and their behavior to visit the flower were observed at certain time and place. Insects were captured with sweep net when they were about to leave, and then were put into a glass bottle with aether, the killed insects were brought back to the lab to be identified, the number of $E$. inderiensis pollens carried by the insects were counted under the dissecting microscope.

\subsubsection{Pollen viability}

When E. inderiensis was at full flowering stage, 10 flowers were chosen to do the following experiment: when the first anther was about to dehisce, its pollens were scattered on a clean glass slide, a drop of 0.1\% TTC (red tetrazoline) was added right away, the number of pollen grains that changed to red color per 200 pollen grains was taken as the pollen viability index. The pollen viability variation in the whole process of anther dehiscence was observed every 20 minutes, until the anther shriveled. The pollen viability index of one anther of the flower was used to deduce the pollen viability of the single flower. Ten flowers were chosen to get an average.

\subsubsection{Pollen grain per flower, ovule per flower and pollen/ovule ration $(\mathrm{P} / \mathrm{O})$}

Added $1 \mathrm{Mol} / \mathrm{L}$ hydrochloric acid to all the pollen grains of single flower, heated at 60 centigrade in water bath for 15 minutes to remove the wall of anther, then added distilled water and got $50 \mathrm{~mL}$ microspore suspension, transferred $5 \mu \mathrm{L}$ microspore suspension to a clean glass slide, added a cover plate, and made a statistic analysis of the microspore number under the optic microscope. Repeated ten times and got the total pollen grain per flower. The germen wall of each flower was removed under the dissecting microscope to record the number of ovules of single flower, and get the average ovules of each flower. The pollen grain per flower was divided by the number of ovule and got P/O.

\section{Results and discussion}

\subsection{Flowering Phenology and observation of floral features}

\subsubsection{Flowering phenology and pollination feature}

Observation in 2007 showed that the initial flowering stage, first flowering stage, full flowering stage, end flowering stage and finishing flowering stage of E. inderiensis were $15^{\text {th }}$ May, $18^{\text {th }}$ May, $19^{\text {th }}-31^{\text {st }}$ May, $4^{\text {th }}$ June and $7^{\text {th }}$ June respectively. The flowering sequence of single anthotaxy was from the bottom to the top, anthesis of single flower lasted one day. When the weather was rainy and the highest temperature was 20 centigrade, anthesis of a single flower could last two days. Pollen dispersal for single anther was approximately 40 minutes. 6 anthers matured heterotypically, i.e. the anther dehisced one by one or two at a time (Fig. 3). Pollen dispersal period of single flower could last for 4 to 5 hours from 10:30 to 15:00 local time, so the pollen dispersal period was prolonged to a great extent. After the six anthers shriveled, the perianth didn't change much, but the bottom of the germen produced nectar (Fig 4), which is an important attractant for $E$. inderiensis to attract insects.

\subsubsection{Floral features}

Feature of single flower

When flowering, six perianths don't unwrap, looking like a canister, the bottom of the germen produces nectar, the filaments of six androeciums elongate in succession, anther gradually come out of perianths, and dehisce one by one or two at a time. The anther is orange, the chapiter looks like needle, and protrudes out of perianths aslant (Fig. 2, 1).

\section{Feature of flower group}

The flowers cling to the anthotaxy, which is thin and long. Each plant has 30-40 flowers (Fig. 2). Flowers at the bottom of the anthotaxy bloom first, and then come the upper ones. At full flowering stage, each plant can have 15-20 flowers. Florescence stage is in May and fruit stage is from May to June.

\subsection{Pollination feature}

\subsubsection{Abiotic pollination medium}

It was shown that pollens of $E$. inderiensis were captured on the glass slides, indicating that wind force was one of the 
pollination mediums for E. inderiensis. Pollens could be spread to 70 meters away or more, but the number of pollens decreased with the increase of distance (Fig. 1). No matter the wind speed was $2 \mathrm{~m} / \mathrm{s}$ or $12 \mathrm{~m} / \mathrm{s}$, about $60 \%$ of the pollens were spread to no more than 20 meters. When the wind speed was $12 \mathrm{~m} / \mathrm{s}$, pollens within 20 meters accounted for $70 \%$ of the total pollens. The pollens spread by wind medium increased when the wind power was stronger, so the pollens of $E$. inderiensis could be spread by wind more easily.

\subsubsection{Biotic pollination medium}

The main pollinators that visit the E. inderiensis belong to Apidae, Halictidae, Syrphidae, Bombyliidae and Therevidae in the nature. The anthers of $E$. inderiensis are close to each other, so when the insects visit the flower, it is easy for them to take away pollens. When the weather is rainy and cloudy, or at low temperature, i.e. the highest temperature is less than 20 centigrade, there are few insects in the desert. Insects are more active from 10:30 to 13:30 every day.

\subsection{Pollen grain per flower, ovule per flower, pollen/ovule $(P / O)$ and pollen viability}

The number of pollen grains per flower of E. inderiensis is 241840; the number of ovules per flower is 12 , so the pollen ovule ratio is 20153. According to Cruden's breeding system (Cruden and Hermann-Parker, 1977), if the pollen ovule ratio ranges from 2.7 to 5.4 , it is cleistogamy, if the pollen ovule ratio ranges from 18.1 to 39.0 , it is obligate autogamy, if the pollen ovule ratio ranges from 31.9 to 396.0 , it is facultative autogamy, if the pollen ovule ratio ranges from 244.7 to 2588.0, it is facultative xenogamy, and if the pollen ovule ratio ranges from 2108.0 to 195525.0, it is obligate xenogamy. It can be seen that $E$. inderiensis belongs to obligate xenogamy breeding system.

The pollen viability of one anther of the flower indicates that the pollen viability gradually decreases with the progress of anther dehiscence, when the anther is about to shrivel, the pollens are still viable; the average pollen viability in the whole process of dehiscence is $94.8 \%$.

\section{Discussion}

\subsection{Floral feature and pollination strategy by insects}

The floral structure and feature influence the behavior of visitors and the pollination mechanism and accordingly influence the reproductive success rate of female parent (pollen acceptor) and male parent (pollen donor) (Spira, et al., 1992; Fishbein and Venable, 1996). The attractants, i.e. the floral feature, including nectary, pollen, smell and color, are the main factors to maintain the relationship between flower and pollinator.

E. inderiensis lives in the desert, where the temperature is high, the air is dry and wind is strong with sand, in addition, the pollinators are uncertain, the unadvantageous conditions will influence the pollination and existence and reproduction of the plant. E. inderiensis has no colorful flowers; the main attractants are the orange anther and the nectar at the bottom of germen. The germen is wrapped by the corollas, so the nectar will be protected from high temperature, heat, wind and sand, so as to attract insects; this is an adaptation of Eremurus inderiensis to the habitat in the desert.

\subsection{Heterotypical maturation of anther is the adaptation to the extreme desert environment}

As shown in Fig. 4 that the anthers of Eremurus inderiensis mature heterotypically. In the dry, hot and windy desert, the pollen dispersal time is short, and the activities of insects are restricted to a great extent, only if the insect visit the flower several times, can all the pollens be spread out. The heterotypical maturation of anther is the adaptation to the visiting behavior of insect, the heterotypical maturation of six anthers of Eremurus inderiensis will greatly prolong the pollen dispertion time of single flower, and it will increase the possibility to meet the pollinators, and improve the pollination efficiency.

\section{References}

Cruden R W and Hermann-Parker S M. (1977). Temporal dioecism: An alternative to dioecism? Evolution. (31): $863 \sim 866$.

Cui, Nairan. Mao, Zumei and Li, Xueyu. (1996). The Plant Index of Xinjiang. Volum 6. [M] Urumchi: Xinjiang Science, Technology and Sanitation Publishing House. 480-482.

Douglas K L. and Cruden R W. (1994) The reproductive biology of Anemone Canadensis: breeding system and facilitation of sexual selection. Amer. J. Bot. (81): 314 321.

Fishbein M and Venable DL. (1996). Diversity and temporal change in the effective pollinators of Asclepias tuberosa [J]. Ecology. 77 (4): 1061 1073.

Spira TP. Snow AA. Whigham DF and Leak J. (1992). Flower visitation, Pollen deposition, and pollen-tude competetion in Hibiscus moscheutos (Malvaceae). American Journal of Botany. 79 (4): 428 443.

Wang, Xueqin and Jiang, Jin. (2003). The distribution of ephemeral vegetation on the longitudinal dune surface and its stabilization significance in the Gurbantunggut Desert. [J]. Acta Geographica Sinica. 58 (4): 598-605. 
Zhang, Liyun. Liu, Su and Zhou, Xingjia. (1998). Vegetations in Gurbantunggut Desert and the influence by engineering. [J]. Arid Zone Research. 15 (4): 16-20.

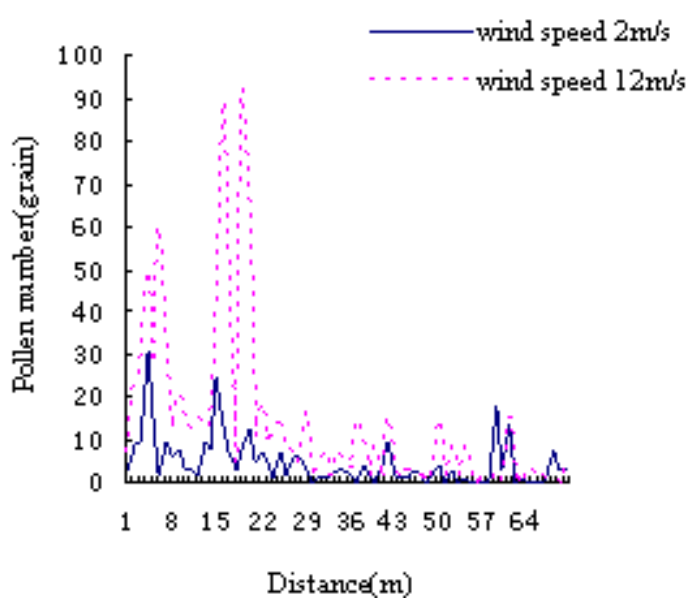

Figure 1. Pollen dispersal of Eremurus inderiensis by wind
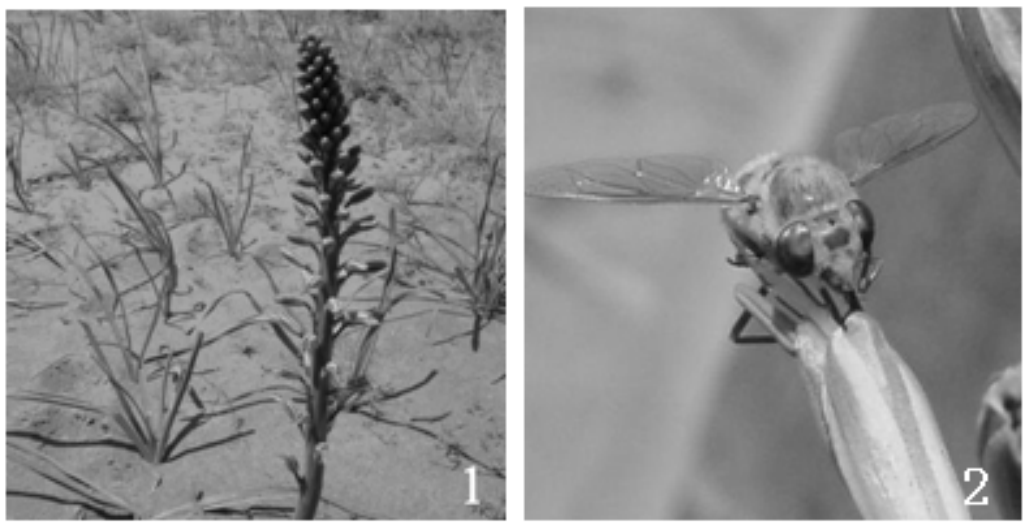

Figure 2. Flower of Eremurus inderiensis
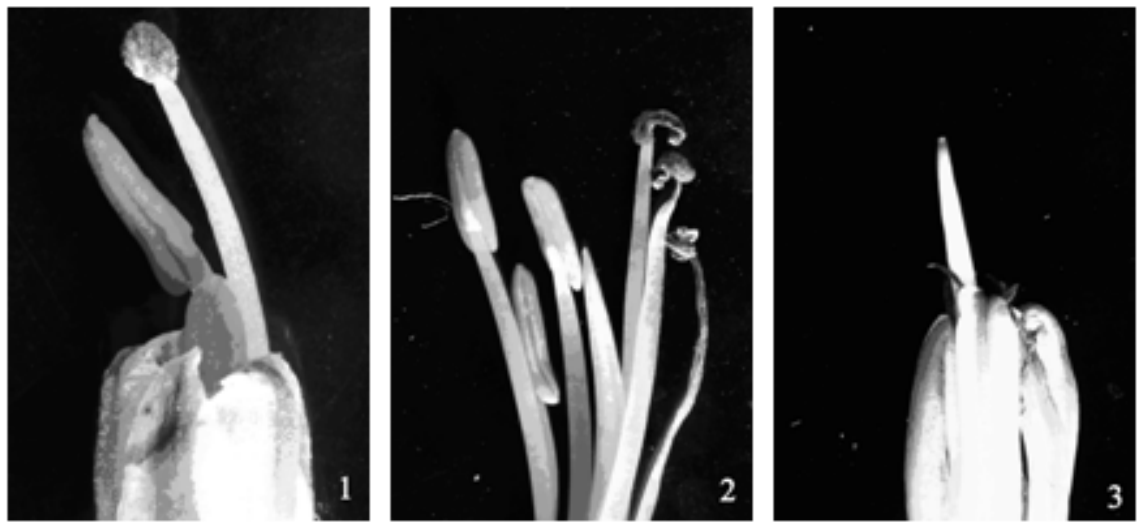

Figure 3. Pictures of heterotypical maturation of Eremurus inderiensis's stamina. 1, one anther dehisced; 2 , three anthers dehisced; 3 , all the anthers dehisced and the gnoecia protrude out of the perianths. 

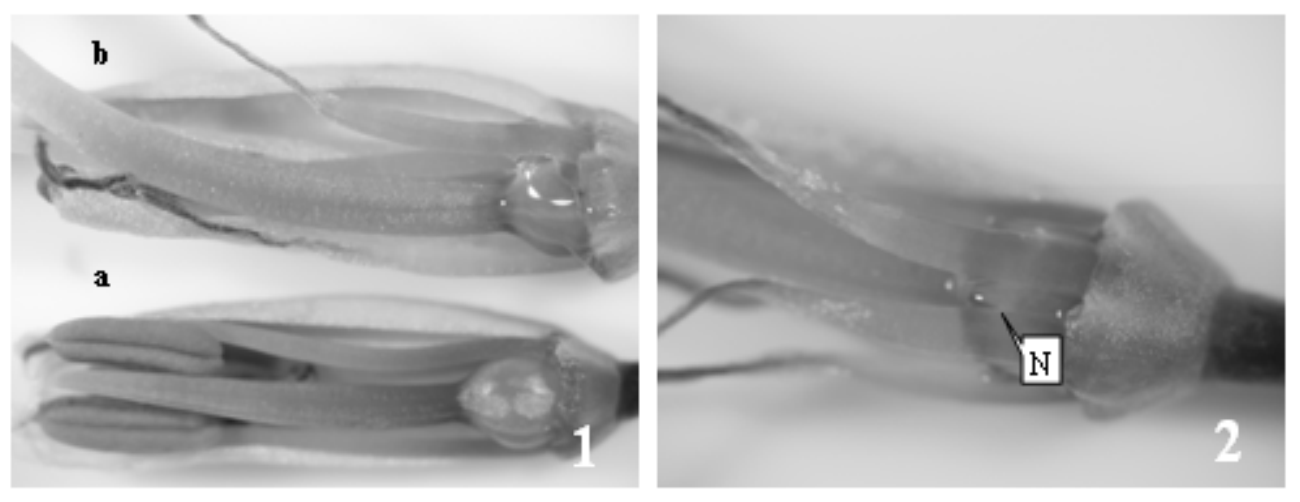

Figure 4. The secretion of Eremurus inderiensis at the bottom of ovary. 1, the secretion of Eremurus inderiensis at the bottom of ovary ( $a$, anther un-dehisced, no nectar; $b$, anther dehisced and shriveled, with nectar). 2 , the secretion of Eremurus inderiensis at the bottom of ovary (anther dehisced and shriveled, with nectar; $\mathrm{N}$, the nectar is bright) 